\title{
Strategy of economic and social development of St. Petersburg until 2030 achievement
}

\author{
Olga Kalchenko ${ }^{1 *}$, Svetlana Evseeva ${ }^{2}$, Oksana Evseeva ${ }^{1}$, and Kristina Plis $^{3}$ \\ ${ }^{1}$ Graduate School of Management and Business, Institute of Industrial Management, Economics and \\ Trade, Peter the Great St. Petersburg Polytechnic University, Polytechnicheskaya 29, 195251 St. \\ Petersburg, Russia \\ ${ }^{2}$ Graduate School of Service and Trade, Institute of Industrial Management, Economics and Trade, \\ Peter the Great St. Petersburg Polytechnic University, Polytechnicheskaya 29, 195251, St. Petersburg, \\ Russia \\ ${ }^{3}$ International Graduate School of Management, St. Petersburg State Marine Technical University, \\ Locmanskaya 3, 190121 St. Petersburg, Russia
}

\begin{abstract}
The paper focuses on the goals' achievements of the Strategy of economic and social development of St. Petersburg until 2030. Strategic directions of St. Petersburg development until 2030 (human capital development, improving urban environment, providing sustainable economic growth, ensuring effective governance and civil society development) are examined. The feasibility of economic and social development indicators, predicted in 2012 for 2020 and 2030, is verified on the basis of actual data for 2016. The indicators, predicted values of which are hard-to-reach and require revision, are revealed. Such indicators are: employed in economy, percent of people with higher education, workplaces with high labor productivity and foreign investment in economy of St. Petersburg. The paper examines the dynamics of the main indicators presented by the Committee for Economic Policy and Strategic Planning of St. Petersburg. The list of indicators is not exhaustive. The Strategy is based on the UN sustainable development goals and one of its scenarios has prospects for implementation.
\end{abstract}

Key words: strategy, economic, social, indicators, Russia, St. Petersburg

\section{Introduction}

St. Petersburg is one of the most developed Russian cities in terms of economy, innovation, industry, culture and social infrastructure $[1,2]$.

In 2015, St. Petersburg became the winner in the ranking of the Association of innovative regions of Russia in the framework of the "Open innovations" forum and also took the 48th place out of 442 in the ranking of innovative cities in the world according to the portal "Innovation cities Program" [3].

St. Petersburg economic and social development is of particular interest as a federal city in Russia.

\footnotetext{
* Corresponding author: kalchenko oa@,spbstu.ru
} 
Research methods used: structural analysis, synthesis, comparison and generalization, deduction and induction.

The initial data are the statistical data from PetroStat, Committee for Economic Policy and Strategic Planning of St. Petersburg, government of St. Petersburg and The Strategy of economic and social development of St. Petersburg until 2030.

The paper is aimed at verifying the feasibility of the main economic and social development indicators, projected in 2012 for 2020 and 2030, on the basis of actual data for 2016.

\section{The strategy of economic and social development of St. Petersburg until 2030}

The Strategy of economic and social development of St. Petersburg until 2030 is based on the sustainable development goals, outlined in The United Nations report "Our Common Future" over 30 years ago $[4,5]$.

The Strategy was created with the assistance of leading international experts in economy and strategy planning and defines the future of the city for the next 15 years. The Strategy is the complex document, which contains justification of developmental scenario of St. Petersburg and description of priorities of a long-term development of the city on the basis of priorities of the Russian Federation. It also defines mission and purposes' systems of economic and social development of St. Petersburg for the period till 2030. The Strategy was adopted in May 2014 [6].

Initially, 3 scenarios of the Strategy were developed: conservative, moderately optimistic and innovative. As the main scenario, the innovative one is chosen.

Priority functions of St. Petersburg:

- a multifunctional city, providing comfortable conditions and high quality of life,

- the leader of the Baltic Sea region,

- an outpost of the Arctic exploration,

- the center of culture, science, education, tourism, and high-tech industry.

The general objective of the Strategy: Ensuring the stable improvement of the quality of life in the city and an increase of the global competitive position of St. Petersburg by achieving the national development priorities, ensuring a sustained economic growth, and using the results of innovation and technology development.

Strategic areas aimed at achieving the general objective of the Strategy and the main priorities of St. Petersburg development until 2030 are also consistent with the sustainable development goals. Strategic directions are: human capital development, improving urban environment, providing sustainable economic growth, ensuring effective governance and civil society development [7].

\subsection{Human capital development}

\section{Demographic development:}

- permanent population will increase to 5,9 million people (in $2012-5$ million people);

- city population increase due to migration will range from 40-70 thousand people per year;

- mortality rate will decrease to $11.3 \mathrm{ppm}$ (in 2012 - 12.4).

\section{Development of the public health system:}

- increase in life expectancy to 78 years;

- mortality reduction from all causes per 1,000 people up to $11.3 \mathrm{ppm}$;

- ratio of doctors and nurses 1:3,5. 


\section{Development of education, including professional:}

- availability of pre - school education will be at least 100\% (in $2012-95.65 \%$ );

- ratio of the unified state exam (USE) average score in 10\% of schools with the best exam results to the average score in $10 \%$ of schools with the worst exam results in the main subjects will be 1,1 and 1,07 respectively (in $2012-1,42$ and 1,82 respectively);

- value of the education index will be 0,984 (in $2012-0,971$ ).

\section{Development of culture:}

- share of cultural heritage objects in satisfactory condition in the total number of objects of cultural heritage of federal, regional and local (municipal) importance will reach $100 \%$;

- attendance of all types of cultural institutions will be at least 3 times per 1 inhabitant per year.

\section{Development of tourism:}

- number of tourists entered the city for various purposes will reach 10 million people a year;

- capacity of the city hotel complex will be 45 thousand rooms;

- share of sea, river cruise and resort tourism segments will increase by $15 \%$;

- number of resort complex rooms will reach 15 thousand (will increase more than 2 times) and will create a modern infrastructure of outdoor activities.

\section{Development of physical culture and sports:}

- proportion of residents, systematically engaged in physical culture and sports, will reach $50 \%$;

- number of sportsmen-dischargers and masters of sports will increase by $40 \%$;

- proportion of people with disabilities and disabled people who are systematically engaged in physical training and sports will be 40 thousand people (in $2012-24.2$ thousand people); - up to 1.15 people for 10 thousand inhabitants will increase the number of athletes of high qualification, prepared for the reporting year.

\section{Development of social support system for citizens:}

- Giny coefficient, which characterizes the stratification of society by income, can drop to 0.440 (in $2012-0.442$ );

- proportion of the population living below the poverty line will not exceed $8 \%$ of the total population (in $2012-9.2 \%$ ).

\section{Providing affordable housing for citizens:}

- indicator of the average level excess of the interest rate on the mortgage housing loan in relation to the consumer price index will be reduced to a level not exceeding 2.2 percentage points;

- number of issued mortgage housing loans will increase to 4,200 per year;

- share of communal apartments in the total number of apartments will not exceed $1 \%$.

\subsection{Improving urban environment}

\section{Improvement of urban territories:}

- the main direction of development is the transition from the regulatory and distributive principle of management to the program-investment principle;

- within the framework of the project management system, it will be possible to plan the direct and indirect effects of budget investments.

\section{Improvement of city ecology:}

- reduction of air and water basins pollution by $20 \%$ compared to the level of 2013;

- air and water environment will be $100 \%$ compliant with the regulations of the Baltic region. 


\section{Development of the transport system:}

- 18 new metro stations and 4 additional lobbies of existing stations will be built, which will ensure pedestrian accessibility of metro stations for $55 \%$ of the population;

- by 2030, the metro network will consist of 89 stations;

- at least $75 \%$ of all population movements will be carried out by public transport.

Development of energy and engineering infrastructure:

- transformer capacity of $110 \mathrm{kV}$ network will increase to 21,356.0 MVA;

- installed heat capacity of heat supply sources will be at least $31003.2 \mathrm{Gcal} / \mathrm{hour}$;

- capacity of head structures of the water supply system will be 2800.0 cubic meters/day;

- capacity of the drainage system will reach $2,444.5 \mathrm{~m} 3 /$ day

Territorial development of St. Petersburg:

- transition to complex development of territories of the city;

- clarification of the borders;

- adjustment of the functional zoning of territories associated with the placement of objects of engineering and transport infrastructure;

- clarification of the boundaries of protected natural areas.

Development of St. Petersburg agglomeration:

- strengthen the importance of small and medium-sized cities;

- reduce differences in the quality of life of the population by ensuring the availability of social, communal and household infrastructure, including through the creation of transport links;

- improve the environmental situation.

\subsection{Providing sustainable economic growth}

Economic development, establishment of bases of knowledge economy:

- share of St. Petersburg's economy in Russia's economy will increase to at least $8 \%$ (3.8\% in 2012);

- share of knowledge economy in gross disposable income of St. Petersburg will be at least $35 \%$;

- the demand for qualified personnel will be provided by at least $80 \%$ of highly qualified employees of St. Petersburg;

- number of high - performance jobs will increase to at least 400 thousand units (in 2012 102,7 thousand).

- degree of fixed assets depreciation will be reduced to 30\% (2012 - 39.2 per cent).

Innovation and technological development of industry:

- share of high-tech industry in gross disposable income will be at least $25 \%$;

- share of innovative products in the total volume of shipped products in St. Petersburg should be at least $30 \%$ (12.1\% in 2012);

- output per industrial worker will increase by at least 2.5 times (in 2012 prices);

- number of advanced production technologies will increase to at least 450 (in 2012 - 259).

Development of science and innovation activity:

- share of high-tech and knowledge-intensive sectors in gross disposable income will be at least $25 \%$ (in $2012-15.6 \%$ );

- at least 17 thousand advanced production technologies per year will be used in economic activities (in $2012-6.5$ thousand)

- number of personnel engaged in research and development will increase to 114 thousand people (in $2012-80.7$ thousand people).

Development of the system of continuous education, training and retraining of highly qualified staff for the knowledge economy:

- a closer link between vocational education and labour market needs is required. 


\section{Development of trade and consumer markets:}

- increase of St. Petersburg budget taxation revenues from implementation of trade activity and services by $20 \%$ in comparison with indicator of 2012 ;

- decrease of consumer goods price index level in comparison with the current period by $15 \%$;

- reduction of three largest suppliers share in retail chains to $45 \%$.

Small business development:

- number of small enterprises, including microenterprises, will reach 340 thousand units:

- share of employees of small and medium-sized enterprises in the total average number of employees will reach 50\%;

- indicators will allow St. Petersburg to take the World Bank ranking position on favorable business conditions at least 10th.

\section{Development of the construction industry:}

- volume construction works will reach 1480.0 billion rubles (in 2012 - 353.1 billion rubles.);

- total housing area input in St. Petersburg will amount to 4.1 million sq. m.;

- total housing stock area will increase to approximately 182 million square metres (a $52 \%$ increase compared to 2012).

Development of the real estate market and support of development projects:

- investments into fixed assets will increase to 3,000 billion rubles (in $2012-351.9$ billion rubles);

- investments per capita will increase up to 511.1 thousand rubles. (in $2012-70.5$ thousand rubles).

Providing activity connected with Arctic zone development:

- at least $50 \%$ of all purchases (goods, works and services) will be carried out by enterprises and organizations of St. Petersburg (Krylov State Research Centre, shipyard "Severnaya Verf", JSC "SPMBM" Malakhit", etc.);

- $60 \%$ of the total research amount on Arctic issues will be carried out by St. Petersburg scientific organizations;

- $15 \%$ of St. Petersburg employees will be involved in projects and programs related to the Arctic zone development.

Development of creative industries:

- contribution of creative industries to the formation of St. Petersburg gross disposable income will increase to $12 \%$;

- ratio of professionals in creative industries in relation to the total number of able-bodied population in St. Petersburg will be $16 \%$.

\subsection{Ensuring effective governance and civil society development}

Improvement the quality of public management:

- share of population positively assessing the executive authorities activities will be $60 \%$;

- share of public services that the population can receive using modern technologies will be $100 \%$.

Providing personal and public safety of citizens:

- reduction of deaths in road accidents per 100 thousand people by $40 \%$ compared to 2012 ;

- reduction of thefts and crimes connected with drug trafficking to 15,2 thousand and 8,9 thousand a year, respectively;

- increase in number of police districts to 632 units per 10 thousand people.

Better integration of young people in modern society:

- the proportion of young people enrolled in vocational guidance services will be at least $80 \%$ of the total number of students; 
- the proportion of socially supported minors and young people from the total number of those registered will be $90 \%$ of the total number of registered persons;

- the proportion of minors and young people covered by prevention of drug addiction, will be $50 \%$ of the number of minors and youth.

\section{Development of interethnic and interfaith relations:}

- reduction of crimes committed by migrants - by $40 \%$ compared to 2013 ;

- reduction of crimes against migrants - by $40 \%$ compared to 2013 ;

- reduction of illegal migrants - by $80 \%$ compared to 2013 .

Development of relations with social organizations:

- increase in the number of non-profit organizations - more than 3 times (compared with 2012);

- share of purchased goods, works and services for state and municipal needs realized nonprofit organizations will increase by more than 5 times (in comparison with 2012);

- number of volunteers in the non-profit sector will increase by more than 4 times (compared to 2012).

The implementation mechanism of the Strategy involves the monitoring of its performance, which allows to control the achievement of the planned results during the social and economic development of St. Petersburg, based on a comprehensive assessment of targets and benchmarks of the Strategy and state programmes in St. Petersburg.

It is assumed, that combining the efforts of government, businesses, and society will allow St. Petersburg to succeed in the implementation of the Strategy and become a fully global city with a comfortable habitat.

Table 1. Resource background of the strategy

\begin{tabular}{|l|c|c|c|c|c|}
\hline \multirow{2}{*}{ Main indicators } & 2012 & 2016 & 2020 & 2030 \\
\cline { 2 - 6 } & \multicolumn{2}{|c|}{ Actual data } & \multicolumn{2}{|c|}{ Predicted data } \\
\hline Employed in economy (thousand people) & $2,530.4$ & $2,970.5$ & $2,966.9$ & $3,174.2$ \\
\hline Percent of people with higher education & $44.7 \%$ & $42.3 \%$ & $47.0 \%$ & $50.0 \%$ \\
\hline $\begin{array}{l}\text { Workplaces with high labor productivity(thousand } \\
\text { units) }\end{array}$ & 102.7 & 783.1 & 280 & 400 \\
\hline Water use (thousand cubic meter per day) & 1,625 & 1,416 & 1,500 & 1,500 \\
\hline $\begin{array}{l}\text { Gross Regional Product of Saint-Petersburg (billion } \\
\text { roubles) }\end{array}$ & $2,530.4$ & $3,742.2$ & $5,310.5$ & 14,000 \\
\hline Fixed capital investment (billion roubles) & 351.9 & 582.3 & 982.7 & 3019 \\
\hline $\begin{array}{l}\text { Foreign investment in economy of Saint-Petersburg } \\
\text { (billion USD) }\end{array}$ & 10.8 & 4.8 & 15.2 & 17 \\
\hline Consolidated budget revenues (billion roubles) & 379.9 & 476.7 & 648.3 & 1401.4 \\
\hline Consolidated budget expenditures (billion roubles) & 382.3 & 496.5 & 630.9 & 1401.4 \\
\hline
\end{tabular}

Source: Own processing based on [7-9].

According to statistics for 2016, some indicators differ significantly from the predicted for 2020-2030. Particular attention should be paid to: employed in economy, percent of 
people with higher education, workplaces with high labor productivity and foreign investment in economy of St. Petersburg.

Fig. 1 clearly shows that in 2016 the number of employed in the economy exceeded the predicted data for 2020. The forecast for 2020 needs to be revised.

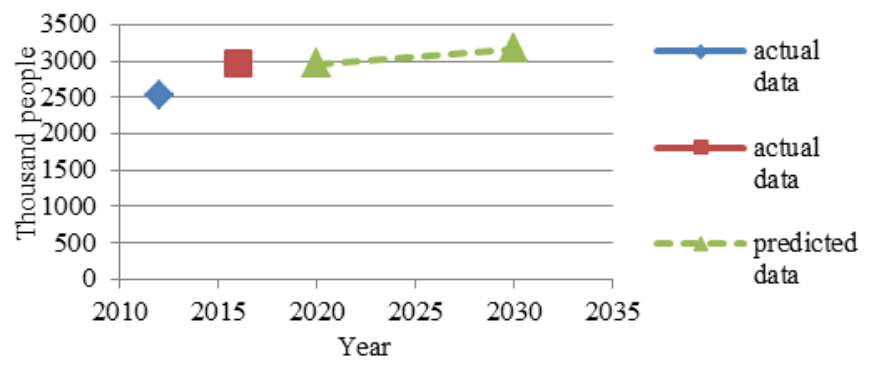

Fig. 1. Employed in economy.

Source: Own processing based on [7-9].

The percent of people with higher education, on the contrary, in 2016 decreased compared to 2012, as can be seen in Figure 2.

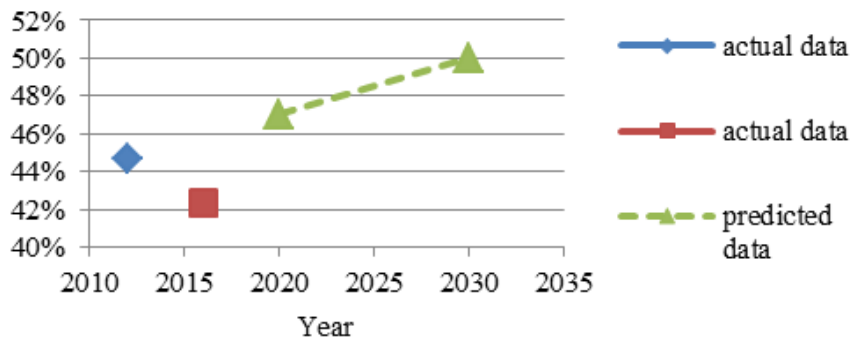

Fig. 2. Percent of people with higher education.

Source: Own processing based on [7-9].

Fig. 3 reflects a significant leap in the number of workplaces with high labor productivity in 2016, which exceeds forecasts for 2020 and 2030. Accordingly, the forecast also needs to be revised.

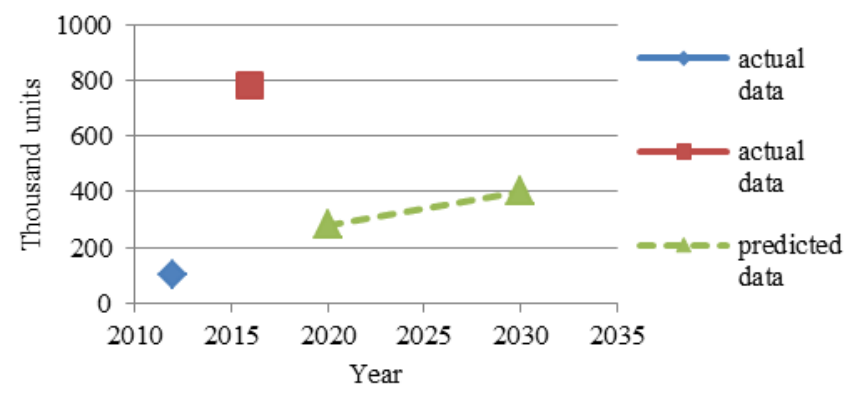

Fig. 3. Workplaces with high labor productivity.

Source: formed by author based on [7-9]. 
Foreign investment in economy of St. Petersburg in 2016 significantly decreased even compared to 2012 . Forecasts for 2020 and 2030 are seen as weakly achievable and need to be revised.

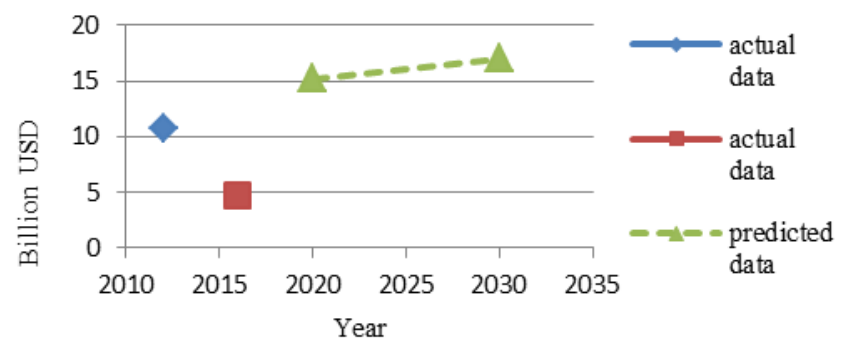

Fig. 4. Foreign investment in economy of Saint-Petersburg.

Source: formed by author based on [7-9].

Other indicators of the Table 1 are within the predicted ranges and are achievable.

\section{Conclusions}

An updated strategy until 2035 was recently presented by the Committee for Economic Policy and Strategic Planning of St. Petersburg (CEDIPT) [10]. Unfortunately, information on whether the predicted indicators highlighted in the paper have been revised is not yet available. This represents the limitation of the study and provides opportunities for future research.

During the paper preparation, a greater number of indicators were revealed on various information portals of the St. Petersburg government, committees, and statistical services and in policy documents $[11,12]$. For the study, the main indicators were selected, according to CEDIPT.

Current strategy until 2030 and updated strategy until 2035 are fully consistent with the UN sustainable development goals and one of its scenarios has prospects for implementation [13, 14]. A number of pilot innovative projects in St. Petersburg are aimed at sustainable urban development. Major research universities take part in the implementation of most of those projects; some of them are supported by instruments of cooperation across borders through project funding $[15,16]$. Cooperation, exchange of experience, joint financing make it possible to achieve sustainable development goals and indicators of economic and social development of such a large European city as St. Petersburg.

This paper was financially supported by the Ministry of Education and Science of the Russian Federation on the program to improve the competitiveness of Peter the Great St. Petersburg Polytechnic University (SPbPU) among the world's leading research and education centres in the 2016-2020.

\section{References}

1. O. Golubchikov, World-city-entrepreneurialism: globalist imaginaries, neoliberal geographies, and the production of new St Petersburg. Environment and Planning A, 42(3), 626 (2010)

2. J. O'Connor, Creative Exports: Taking Cultural Industries to ST Peterburg. International Journal of Cultural Policy, 11(1), 45-60 (2005) 
3. Association of innovative regions of Russia [online], Available at: http://iregions.org/eng/ (2019)

4. Assembly UN General "The Future we want (Resolution adopted by the General Assembly on 27 July 2012) [online], Available at: http://www.un.org/disabilities/documents/rio20_outcome_document_complete.pdf. (2012)

5. Report of the World Commission on Environment and Development: Our Common Future [online], Available at: http://www.un-documents.net/our-common-future.pdf (2019)

6. Strategy of economic and social development of St. Petersburg until 2030 [online], Available at: http://spbstrategy2030.ru (2019)

7. Strategy of economic and social development of St. Petersburg until 2030. CEDIPT [online], Available at: http://cedipt.spb.ru/media/acts/2015/12/09/Strategy_of_economic_and_social_develop ment of St._Petersburg until 2030.pdf (2015)

8. PetroStat [online], Available at: http://petrostat.gks.ru/ (2019)

9. Government of St. Petersburg resolution [online], Available at: http://gov.spb.ru/law?d\&nd=822403603\&nh=1 (2019)

10. S. Evseeva, O. Kalchenko, O. Evseeva, Circular economy for the energy transition in Saint Petersbutg. MATEC Web of Conferences: International Science Conference SPbWOSCE-2017 “Business Technologies for Sustainable Urban Development”, 170 (2018)

11. A.R. Bril, O.V. Kalinina, I.V. Ilin, Sustainable Economic Growth, Education Excellence, and Innovation Management through Vision 2020. Proceedings of the 29th IBIMA Conference, pp. 2268-2277 (2017)

12. O.A. Kalchenko. Proceed. of the ICTM 2016, 46 (2016)

13. V.V. Okrepilov, V.L. Makarov, A.R. Bakhtizin, S.N. Kuzmina, Application of supercomputer technologies for simulation od socio-economic systems. R-Economy, 1(2), 340-350 (2015)

14. V. Plotnikov, G. Fedotova, E. Popkova, A. Kastyurina, Harmonization of Strategic Planning Indicators of Territories' Socioeconomic Growth. Regional and Sectoral Economic Studies, 15(2), 105-114 (2015)

15. I. Ilin, A. Levina, O. Iliashenko, Enterprise Architecture Analysis for Energy Efficiency of Saint-Petersburg Underground. Advances in Intelligent Systems and Computing: International Scientific Conference Energy Management of Municipal Transportation Facilities and Transport, 692, pp. 1214-1223 (2018) 